https://doi.org/10.37208/tgn27131

\title{
Nomada flava (Hymenoptera: Apidae): first confirmed Scottish record
}

\author{
R.B. Weddle \\ 89 Novar Drive, Glasgow G12 9SS \\ E-mail: richard@canto.plus.com
}

On 31st May 2018, after a tip-off from a local birdwatcher, I visited Carbarns (NS765542, Lanarkshire VC77) on the banks of the Clyde upstream of Baron's Haugh, to collect a specimen of a solitary bee that he had seen a few days before. His photograph was of a Lasioglossum species (indet.), but on my visit, after some searching, I found only bees belonging to the genus Nomada, one of which I collected for identification.

The bee turned out to be a female Nomada flava Panzer, 1798, a cuckoo-bee that lays its eggs in nests of Andrena species (mining bees). Because the previously known range of $N$. flava extended northwards only as far as Durham and Cumbria (Else \& Edwards, 2018), it was necessary to have the identity confirmed by an expert (Murdo Macdonald) who also drew my attention to an account of an earlier 1894 record from the shores of the Cromarty Firth; the 1894 specimens, though conforming to the description of $N$. flava and within the range of the principal host species Andrena scotica, were found in September, outside the usual flight period of March to June, and were therefore "difficult to interpret" (Else \& Edwards, 2018).

I intend to pay another visit to the site in the hope of finding possible host species; on my first visit nesting burrows were evident in the sandy bank, and bee-flies (Bombylius major), another kleptoparasite of solitary bees, were seen there on the same day that the Lasioglossum specimen was observed.

I am grateful to Davie Abraham for drawing my attention to the Lasioglossum bees and the bee-flies, and to Murdo Macdonald for confirming the identities of the Nomada and Lasioglossum specimens.

\section{REFERENCE}

Else, G.R. \& Edwards, M. (2018). Handbook of the Bees of the British Isles. Vol 2. The Ray Society, London. 